NARRATIVES OF LGBTQ+/NON-HETEROSEXUAL EAST ASIAN WOMEN

By

Nancy Tran, BSW, University of Windsor, 2018

An MRP

presented to Ryerson University

in partial fulfillment of the

requirements for the degree of

Master of Social Work

in the Program of

Social Work

Toronto, Ontario, Canada, 2019

(C) Nancy Tran 2019 


\section{AUTHOR'S DECLARATION FOR ELECTRONIC SUBMISSION OF A MRP}

I hereby declare that I am the sole author of this MRP. This is a true copy of the MRP, including any required final revisions.

I authorize Ryerson University to lend this MRP to other institutions or individuals for the purpose of scholarly research

I further authorize Ryerson University to reproduce this MRP by photocopying or by other means, in total or in part, at the request of other institutions or individuals for the purpose of scholarly research.

I understand that my MRP may be made electronically available to the public. 


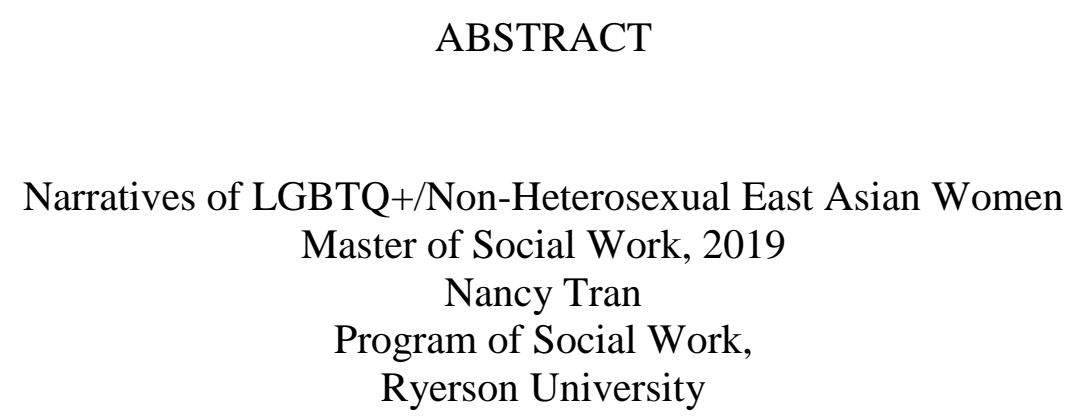

As the title indicates, this paper seeks to explore what the personal narratives and experiences are of LGBTQ+/non-heterosexual East Asian women. I utilised semi-structured, one-on-one interviews with two participants to explore specifically how heteronormativity/homophobia, racism, and sexism have impacted their identity development. This research also looked at the influence of ethnic/cultural backgrounds on the development and understanding of their sexual orientation. The primary findings from the data were that participants experienced guilt and shame for being queer/non-heterosexual from others, and thus repressed their same-gender attractions; participants struggled to reconcile multiple, (seemingly) contradictory identities; participants spoke about the influence of traditional cultural values such as filial piety; and finally, participants identified the broader LGBTQ+ community as being predominantly White and male-dominated. 


\section{Acknowledgements}

First and foremost, I would like to express my deepest gratitude and appreciation to J and Sasha. I am so immensely grateful for and humbled by the both of you in granting me the time, energy, laughter, knowledge, and vulnerability that you both did in being participants and more accurately, co-researchers in this study. None of this would have been possible without you both. Thank you a million and one times over.

Secondly, I would like to express my respect, admiration, and appreciation to:

- Dr. Gordon Pon: your endless, reliable, encouraging support was the foundation upon which I was able to carry out this research. Being in your Practice Research Seminar section gave me the confidence and guidance I needed to tackle a project as daunting as

this one. I could not have asked for a better professor, first reader, and colleague - thank you.

- Dr. Purnima George: thank you for being instrumental in helping me to construct my literature review, but more importantly I would like to thank you for all that you have done to support me and our cohort this year. You are a beacon of strength and tenacity that I aspire to embody one day.

- Dr. Jennifer Poole: thank you for being the second reader for this paper. I deeply appreciated your feedback, comments, and critical questions.

- Notisha Massaquoi: it is an understatement to say that I am indebted to you for all of the kindness, support, wisdom, and guidance that you provided me with - through class, my practicum, and with this paper. I could not have done this without you and I am so grateful for you. Thank you. 
Finally, I would like to thank my chosen family. I may never understand how lucky I am to have found my soulmates and my saviours. Thank you all endlessly for choosing to be a part of my life and for granting me the space to be me in all of my myriad ways. Words are simply insufficient in being able to adequately convey my immense love and gratitude for you all. Thank you. 


\section{Table of Contents}

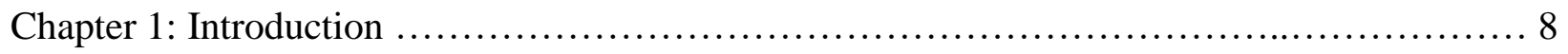

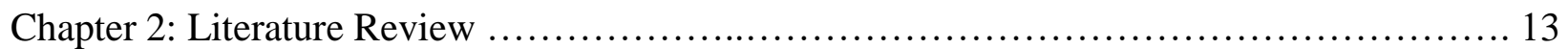

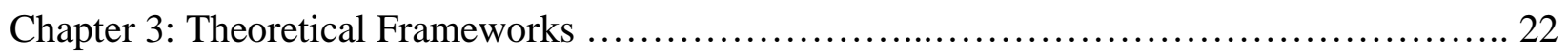

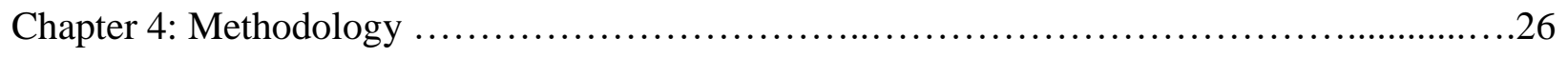

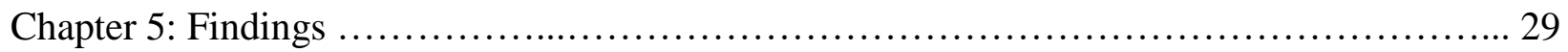

Chapter 6: Discussion \& Analysis ............................................. 47

Chapter 7: Conclusion .......................................................... 52

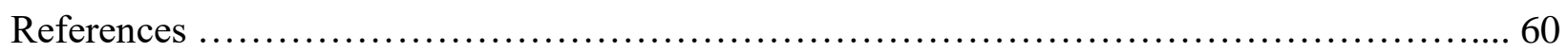




\section{List of Appendices}

Appendix A - Interview Guide ..................................................... 54

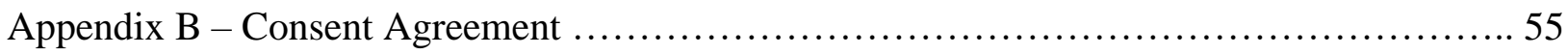




\section{Chapter 1: Introduction}

Korean-American comedian, Joel Kim-Booster, once said that "I literally knew I was gay before I knew I was Asian" (Lau, 2018). Much like Booster, I learned from a young age that I was queer before I realized that I was Chinese - and more specifically, Chinese in a White, settler, colonial context. Of course, once I eventually came to grips with the fact that I possessed both identities simultaneously, things got a little complicated. Although the premise of this paper is to explore the narratives of other LGBTQ+/non-heterosexual East Asian women, it is important that I begin by detailing the aforementioned 'complications', otherwise known as my life story - who I am, where I come from, and how I came to/continue to be. I am the youngest of three first-generation children born to immigrants from Vietnam. Both my mother and my father were first generation children of immigrants from China, who fled to Vietnam in search of a 'better life'. This life never came, however, and so as respective young adults they both made the decision to journey across the globe to Canada during the 1980's. Yet again, they made a journey previously made by their parents to find this seemingly elusive 'better life' for themselves, myself, and my sisters. Although in many ways this notion of Canada as a safe haven for immigrants and refugees is national propaganda, my parents did succeed in attaining this 'better life' for themselves and for their children.

My origin story takes place in Ontario's southernmost city, Windsor, which has a population of roughly 220,000 people and approximately 12,000 East Asians (Windsor 2016 Census, 2018). These humble beginnings were quite interesting, to say the least. I always knew and felt that I was different - different from my sisters, my parents, my culture, the East Asian community, my peers at school, and the people I saw on TV. I spent most of these years resenting myself for not being able to be what everyone else kept trying to tell me I should be. 
I was expected to be a polite, soft-spoken, demure, obedient, feminine, and heterosexual Chinese girl. In every possible way, and much to the detriment of my emotional and psychological wellbeing and self-esteem, I defied these expectations. As a result of this, I constantly felt uncomfortable and was hyperaware of how the rest of the world perceived me. I hated being Chinese, and more specifically, I hated that I was not White. I remember for years wanting so badly to be a part of the happy, functional, normal White images that I saw on TV. I hated that I did not dress 'like the other girls' or like a girl was 'supposed to', and always just wanted to wear clothes from the boy's sections of stores. I spent much of my life up until recently running away from and repressing my ever-present fear that I might be gay (I remember as a child bolting out of any room that had Ellen DeGeneres playing on the TV). I just knew that I could not be anything other than heterosexual - especially not with my family. Up until the last few years, I never really met any other queer East Asian women (or people in general) except for one girl in elementary school. She 'came out' as bisexual during a time when many of my other female classmates were also identifying as such and were beginning to explore their sexualities. At the time, however, I remember being one of many of my classmates who thought that these girls were just attention-seeking or looking to appeal to the male gaze of particular classmates they found attractive. Of course I can now see how bi-phobic these kinds of thoughts were, and also perhaps I can even glean a lot of internalized heterosexism that I personally was struggling with at the time.

In sharing all of this, I think that it is equally important that I recognize all of the nuances of my story. In retrospect, I can appreciate the younger versions of me as a site of resistance against every system that was designed to work against me - against racism, sexism, gender conformity, and homophobia. I know logically that my story is not uncommon, but I know only 
of my story. It is for this reason that I have decided to engage in this research, because I am sure that many others have not been given the opportunity to hear these stories either. I hope that this work will highlight many of the complexities and nuances of the participants' experiences, from navigating White Canadian society as an East Asian body, to reconciling traditional/cultural values and sexual/gender identity.

It is important to me that I help to make visible and provide a platform for those voices that often go unheard in mainstream discourses of race, gender, and sexual orientation. In my own experience, there have been few times and spaces in which I felt that all these different parts of my identity could be accepted and respected - the majority of the time, I can only be East Asian, or a woman, or a queer individual, but rarely a queer East Asian woman. Although Canada is a nation that often boasts about its racial and ethnic diversity, the dominant discourses in general society, academia, and social work typically centre around the Black-White dichotomy. At least in my own experience, East Asian identities often get forgotten and left out of discussions of race and racism. Pon (2000) states that "Antiracism education in Canada is dominated by a Black/White paradigm of race relations that situates historical and contemporary narratives of racial minorities in the shadows of the Black/White encounter" (p. 140). Most discussion of race and racism then, are centred around these two groups whilst largely ignoring the experiences of other racialized groups who do not fit into this dichotomy. The erasure of our oppressions and the pedestaling of us by White people in comparison to other racialized groups can be summed up by the model minority discourse (MMD). As Ho (2002) explains it, the model minority is "an imported American term that refers to Asian Canadians as an exotic, collectivist, and homogenously successful group who are not hampered by the effects of racism" (p. 15). The origin of the MMD is deeply rooted in and driven specifically by anti-Black racism. According 
to Poon et al. (2015), “The model minority label is often attributed to William Petersen (1966), who presented socioeconomic success among a select segment of Asian Americans as an antithesis to African American claims of persistent racial oppression and barriers during the 1960s Civil Rights Movement and at the height of Black-led urban uprisings across the United States" (p. 5). Thus, the creation of the model minority has historically been purposeful, convenient, and strategic for White supremacy and the suppression of Black activism. Although it originated in the United States, the MMD has been shown to be alive and well in a Canadian context. Pon (2015) states that "Throughout the 1980s and 1990s, Canadian presses like the Toronto Star, Fortune Magazine, Globe and Mail, Montreal Gazette, and Toronto Life have championed the Chinese as the "model minority"' (p. 88).

In this study, I used intersectionality and narrative analysis as my methodologies. Utilizing the method of one-on-one, semi-structured interviews, I spoke with participants about their experiences as queer/non-heterosexual East Asian women. Some of the primary findings from the data were that participants experienced guilt and shame for being queer/nonheterosexual from others, and thus repressed their same-gender attractions; participants struggled to reconcile multiple, (seemingly) contradictory identities; participants spoke about the influence of traditional cultural values such as filial piety; and finally, participants identified the broader LGBTQ+ community as being predominantly White and male-dominated.

As will be discussed later on in the Findings and Discussions/Implications sections, queer/non-heterosexual East Asian women face a plethora of systemic barriers and challenges that often go unheard and neglected. Despite having to deal with various systems of oppression, from heterosexism/homophobia to racism to sexism, this particular group of people are not depicted as even existing in Canadian society. The active erasure of us as real people who face 
unique challenges by these systems, as well as challenges from within our own cultural groups. Thus, if we are not even believed to exist, we are silenced and pushed to the sidelines. Nonexistent people do not need support or acknowledgement. I hope that this study highlights and brings closer to the forefront the voices and experiences that belong specifically to queer/nonheterosexual East Asian women that deserve to be seen and heard. 


\section{Chapter 2: Literature Review}

\section{Contextual Background of the Literature}

Prior to discussing the three primary thematic findings of the literature examined, it is necessary to provide a contextual background to the way in which these studies were gathered. Although a variety of methods were utilised in an attempt to locate articles that spoke directly to the population being focused on in my Major Research Paper, it proved to be a difficult task as there is a significant gap in the literature. My strategy, then, and the result of my findings incorporated studies that: a) focused on LGBTQ-specific matters, b) focused on East Asianspecific matters, and/or c) discussed LGBTQ East Asians in some capacity, even if there was not an explicit or in-depth attention paid to women-identified participants. Of the 10 studies, less than half discussed LGBTQ-identified East Asian women at all.

\section{$\underline{\text { Summary of Findings }}$}

Despite a miscellany of articles and foci, two critical themes were observed from the literature. These will be named and discussed in detail below.

\section{Struggles with Identity/ies}

Many of the studies, whether intentionally or not, contended with participants' challenges surrounding their multiple identities and communities of belonging. Park's (1997) study participants, all of whom were of East Asian origin and lived in Canada, struggled with the complex and seemingly irreconcilable relationship between their Asian and Canadian identities. Many expressed feeling as though they did not truly belong to or fit neatly into either category. One participant stated:

I don't feel like I belong. I don't know, I don't feel like I am truly Vietnamese cause I don't truly practice my religion or whatever. Yet I don't truly feel Canadian cause it seems like you are always being noticed as being Asian. You can't, people can never truly 
accept you as being Canadian. You don't know where you belong in term of ethnic origin like what are you. (p. 58)

The Asian-American lesbian and gay participants in Chan's (1989) study articulated a similar grapple, but instead with their racial and sexual minority identities. The author noted from the survey questionnaire responses that the majority of individuals stated that they more strongly associated themselves with their sexual orientation and the lesbian-gay community, in comparison to their racial identities. It was found that this was largely due to traditional Asian values and expectations that stigmatize homosexuality and view it as a "White, Western phenomenon" (p. 19). In another study, two female participants who had highly religious upbringings recalled the emotional and mental toll that subduing their attraction to other girls caused (Logan \& Buchanan, 2008). They both recalled experiencing a great sense of shame and guilt because of how their religious teachings perceived and constructed homosexuality namely, as wrong, sinful, and diametrically opposed to faith.

\section{Implications/Impacts of Heterosexism and Gender Norms}

Another theme that emerged throughout several of the articles was that of heterosexist societal/cultural norms and values, and the plethora of harmful consequences that impact the physical, emotional, and psychological well-being of LGBTQ+ individuals. An American study conducted by Meyer (2012) focused on the intersectional experiences of anti-queer violence/hate crimes committed against LGBT individuals. Drawing heavily upon intersectionality, a term first coined by Crenshaw (1989) to describe the way in which Black women are systemically oppressed based on both their race and gender, the author found that participants perceived antiLGBT acts being perpetrated against them in a variety of different ways based on the multiplicity of their identities. For example, Black and Latino/a participants often felt that others' anti-queer sentiments implied their failure to 'properly represent' their racial communities. Lesbian and 
transgender women participants also noted that physical violence often followed verbal abuse, and typically perceived the physical as being worse. As one participant noted, “...People have called me names in the past. That I can get over. But putting your hands on me, that's a whole new thing. That's what I can't stand" (p. 864).

Nadal et al.’s (2011) study explored LGB individuals' varying responses to microaggressions that targeted their sexual identities. Although microaggressions are different than the more explicit and aggressive discrimination faced by participants in Meyer's (2012) study, they are still violent means of subjugation and oppression. Nadal et al.'s study analyzed and divided participant responses into five themes: “(a) behavioral reactions, (b) cognitive reactions, (c) emotional reactions, (d) mental health, and (e) systems and groups who enact microaggressions" (p. 21). It is evident from just these categories that heterosexist and gender normative attitudes and behaviours greatly affect the well-being of LGBT individuals in a multitude of ways. As discussed in the fifth theme, these microaggressions come from every facet of LGBT people's lives - from family to the education system, and even from the queer community itself - and understandably so, participants expressed such feelings as anger, shame, and sadness. Being under constant emotional and psychological duress from these microaggressions has negatively impacted and perhaps led to the development of mental health conditions such as anxiety and depression.

Wong \& Poon's (2013) study included a group of participants who, as noted in the above article, are amongst the most common perpetrators of microaggressions: parents. As discussed by Chan (as cited in Wong \& Poon, 2013, p. 16), heterosexism and homophobia are deeply ingrained in the society of the participants' country of origin - Hong Kong - due in large part to its history as a former British colony. The researchers challenged many of the participants' 
homophobic and heterosexist values and beliefs through the culturally appropriate Chinese method of storytelling. Through the personal narratives shared by Chinese guest speakers to the group, a gay activist and a mother to a lesbian child, many of the participants spoke of beginning to understand that the issue was not homosexuality but homophobia. The authors cite these counter-narratives as integral to moving beyond just evoking emotional relationality between the speakers and the participants to a place of dismantling deeply ingrained and unchallenged "heteronormative naivety" (p. 24). The authors emphasize through their own research the importance for children's positive identity development to have parents who reject homophobic and heterosexist values and beliefs.

\section{Critical Analysis}

\section{Contributing Disciplines}

Throughout all 10 studies examined in this literature review, it was noted that a wide array of disciplines were involved in the production of these knowledges. The authors all came from or were still working in such disciplines such as psychology, sociology, women's and gender studies, nursing, medicine, business, public policy, and social work.

From analyzing the origins of the authors, it was noted that that half of the studies came from psychology, a field which social work borrows a lot from and shares a lot in common with. Modern, mainstream psychology has often served to pathologize and de-contextualize the experiences of already marginalized individuals (Gable \& Haidt, 2005), so the following observation made of these particular studies may come as no surprise given their foundational discipline. Speaking to the authors' epistemologies, it was noted that four out of the five articles (Chan, 1989; Hiestand, Horne, \& Levitt, 2007; Hu \& Wang, 2013; Logan \& Buchanan, 2008) demonstrated a lack of critical reflexivity. These authors "bracketed" themselves out (Strega \& 
Brown, 2015, p. 8) of the research, which is a highly problematic Western, Eurocentric practice that allowed for them to go about their research whilst ignoring any potential power dynamics between them and the participants, as well as any of their biases that may be consciously or unconsciously affecting the study (Potts \& Brown, 2015). The implication from this means of research is that their participants are merely subjects to be studied and analyzed, and that the researchers themselves are a disembodied and objective presence merely there to extract information. It is critical for all researchers (and perhaps especially for those who wish to do anti-oppressive work) to ensure that they make a conscious and concerted effort to be aware of their own thoughts, emotions, identities, and values in order to challenge complicity in maintaining a hierarchical structure of knowledge that places researchers/institutions at the top and participants at the very bottom.

Perhaps of distinct note and of personal disappointment was that the only two studies whose author had a background in social work (both written by the same researcher) also lacked any critical reflexivity. The articles (Poon, Li, Wong, \& Wong, 2017; Wong \& Poon, 2013) both made no mention of the authors' social locations or positionalities in relation to the research topic and their participants, thus reinforcing many of the criticisms of this top-down approach that were discussed above.

\section{Paradigms and Theoretical Frameworks}

Over half of the studies were shaped by an interpretivist paradigm (Chan, 1989; Logan \& Buchanan, 2008; Poon et al., 2017; Meyer, 2012; Nadal et al., 2011; Park, 1997). Interpretivist social science (ISS) places a great value on the various - but nonetheless true - ways that people create meaning from their interpretations of their experiences and social contexts (Rubin \& Babbie, 2013). ISS, unlike its positivist antithesis, interrogates the ability for social scientific 
research to be free of value or 'bias' because values are inherent in every facet of everyone's lives; this is especially true under interpretivism (Neuman, 2006). For example, self-identified feminist researchers, Logan \& Buchanan (2008), sought to collect the individual experiences of young, queer adolescent women in navigating their sexual identities. The authors utilised both feminist theoretical framework in centering women and their lived experiences (Neuman, 2006), and symbolic interactionism to guide their analysis and categorization of the participants' responses into five distinct themes. Like Logan \& Buchanan's study, the other five articles demonstrated what is perhaps one of interpretivism's greatest epistemological strengths: the positioning and valuing of individuals as the ultimate knowers through the use of frequent quotations. While it is important to highlight people's stories and experiences, such an extensive individualistic, micro-level focus could prove to be detrimental if it leaves little to no room for analyses at the structural level - which, if you were to ask critical researchers, interpretivism can often be found guilty of this (Strega, 2015).

Speaking of critical research, two articles utilised critical social science (CSS) as its primary paradigm (Park, 1997; Wong \& Poon, 2013). If it was to be observed on a spectrum, one would place CSS in between ISS and PSS as a sort of middle ground that shares aspects with both ends. CSS is noted distinctly for its direct challenge to systems of oppression and its call to action-oriented empowerment of people, particularly those directly affected by these systems. (Neuman, 2006). Making use of critical and queer theory, Wong \& Poon's study utilised CSS in its case study of a "community-based family-health promotion programme" (p. 18) for immigrant Chinese parents, which empowered them to do their own community outreach with what they learned. As previously discussed in the Implications/Impacts of Heterosexism and Gender Norms section, the programme's facilitators used a culturally-appropriate method to 
challenge the homophobic beliefs and values that many of these individuals had, which served to frame systemic homophobia as the issue, not homosexuality. The authors also engaged in another demand of CSS, which is described by Neuman as follows: "The critical researcher probes social situations and places them in a larger historical context" (p. 97). Early on in their article, Wong \& Poon provide an explanation/history on the origins of systemic and cultural homophobia in the participants' home country of Hong Kong, thus placing it in the greater structural picture. On the other hand, a crucial limitation to CSS is that its epistemological basis is rooted in the positivistic notion of a discoverable and knowable reality (Strega, 2015, p. 127). In speaking specifically to limitations with this particular study, one critical limitation of ISS would be that it would assert that all individual's interpretations of their reality are valid including homophobic and anti-LGBTQ+ views.

\section{Methodologies and Methods}

Epistemologies, such as the ones described in the previous section, act as the overarching umbrella under which methodologies and methods are developed. In order to ensure internal consistency in the research process, the methodologies, methods, and epistemologies must all be theoretically aligned with one another (Carter \& Little, 2007). Determining one's methodology/ies are of great importance as this affects the types of research questions one asks, as well as the methods one implements in order to collect data. Many of the studies whose disciplines originated from the positivist field of psychology, for example, utilized survey questionnaires (Chan, 1989; Hiestand, Horne, \& Levitt, 2007; Hu \& Wang, 2013). It can be seen in their study of traditional Chinese values on LGB people's sexual identity development that $\mathrm{Hu}$ \& Wang's psychology background influenced their epistemology (positivism), which in turn affected the methodology (mixed methods, cross-sectional), thus determining their primary 
method of data collection (survey questionnaire). While there are many limitations to this methodology and method, the primary weakness that I derive is that the participants are simply reduced to numbers. Their actual voices are not heard, and it serves to reinforce oppressive 'scientific' notions that they are merely objects of knowledge extraction for the 'real knowers', in this case researchers, to try and measure their disembodied responses, to produce some kind of truth as a result.

Those studies that were guided by an interpretivist epistemological paradigm often used methodologies such as phenomenology, narrative analysis, and intersectionality frameworks, which typically manifested into interviews and focus groups. This makes a lot of sense in terms of internal consistency because it is through engaging in dialogue with one another that we can begin to understand how people interpret and understand the world from their own unique perspectives. One critical limitation to the interview method is that there is still a significant power dynamic that can and does occur in the space between the researcher and the 'researched', especially given the high ranking that researchers (usually associated with powerful organizations and/or institutions) have in the world of knowledge production. More often than not, as Chilisa (2012) describes, these methods involve the "dominance of Western academic disciplines' theories, terms, and concepts in shaping interview questions and analyzing interview transcripts" (p. 203). A way to challenge these epistemic issues is to demonstrate critical reflexivity and to break the silence that is expected of researchers' in dialogue, as can be seen in Park's (1997) study. Park explained that throughout the interviews with her participants, she frequently and explicitly reminded participants of aspects of the study such as its goals, the participants' role, and their rights; used common language and omitted incomprehensible jargon; built rapport by engaging in casual dialogue with the participants in order for them to get to 
know each other better; used the second interviews that she had with seven of the eight participants to ensure the accuracy of the statements made in the first interviews; and finally, Park was open to sharing her own thoughts and opinions when asked by the participants as she felt it was disingenuous not to.

Who Is Missing?

In the studies that focused on queer-identified individuals, it was noted that the majority of them did not acknowledge or attempt to include trans participants, or if they did have trans participants, there was often little to no discussion about the kinds of experiences distinctive to trans-identified individuals. For example, Nadal et al. (2011) noted that their study "only included LGB individuals (and not transgender or gender-nonconforming people), as microaggressions involving transgender identity differ, hold additional complexities, and warrant separate studies" (p. 25). While this is certainly true, there is an urgent need then for more literature and research to be done on this group of people. Trans individuals, while facing transphobia and cissexism from the greater cis- and heterosexist society, also face marginalization from within the queer community itself "through silence, exclusion, or outright discrimination" (Jones, 2014, p. 27). It is vital then as researchers who wish to highlight people's narratives and to challenge oppressive structures that we fight for the liberation of all, especially those who are most often pushed aside and silenced. 


\section{Chapter 3: Theoretical Frameworks}

The theoretical frameworks that I felt were most suitable for the kind of research I wanted to undertake were queer theory and critical race feminism. For what each theory may lack or fail to address, the other one fills in the gap in order to create a more holistic and wellrounded overall framework. For each one in the subsections below, I will outline: my rationale for choosing it, its history and evolution over time, some of the key scholars involved, and an explanation as to how I intend to incorporate it into the data analysis.

\section{Queer Theory}

“...queer theory pries open discussions of sexual subjectivities, implicating everyone in the conversation, to make teaching and learning about sexual difference inclusive, fluid, and complicated. As messy as sex."

(MacKinnon, 2010, p. 3)

The term 'queer' in and of itself is a juxtaposition to the hard-lined, rigidly-defined and binaristic understandings that proliferate in today's White, western, Eurocentric, colonial North America. Over the course of its 500 year history, queer is a term that has been used to: describe those who were 'eccentric', define the conditions of the poor, condemn and oppress those who were not straight, and take back power and resist essentialist depictions of what sexuality and gender are or can be (Mulé, 2010). Queer is a way of thinking and being, and is a push back against what is 'normal' and/or 'natural'.

Queer theory is an area of study that was developed and launched during the 1990's as the academic offshoot based off of decades of activism by those in the LGBTQ+ community (Watson, 2005, p. 69). Notable scholars of queer theory include Jasbir Puar, Roderick Ferguson, 
Gloria Evangelina Anzaldúa, Sara Ahmed, Eve Kosofsky Sedgwick, and Judith Butler.

According to MacKinnon (2010),

Queer challenges clear-cut notions about sexual identity through blurring the boundaries between identity categories. Queer theory is about being playful with ideas and turning knowledge inside out and backward. Rather than relying on taken-for-granted categories of straight and gay, queer theorists invite a questioning of all sexuality and a critical unpackaging of how we know what we think we know. (p. 3)

When I am asked as to how I label my sexual orientation, I use 'queer' as an undefinable definition. I give the explanation to people who do not identify in the LGBTQ+ community that it is 'a label that is not a label'. It is comfortable for me in the sense that queer acts as the umbrella under which I stand, safely tucked away beneath a hailstorm of pellets that attempt to attack me with clean-cut and rigid labels such as 'lesbian' or 'gay'. It is also uncomfortable, however, because I am someone who does like to know exactly what everything is labeled and defined as. Uncertainty, fluidity, and blurriness are all qualities that do not sit well with those of us who have grown up in a White, Eurocentric, colonial context. Even just saying the word to particular people causes me discomfort because saying it out loud itself is a practice of resistance to the checkboxes of 'straight', 'gay', 'lesbian', or 'bisexual'. I have been told countless times that even just the way that I carry myself sends a message to the rest of the world that I inhabit a queer body, long before my actual words can.

I hope to utilise the aforementioned tenants of queer theory in order to provide a lens of rich, open, limitless complexity in the way that I approach both my participants and their stories. I will challenge myself to resist, unlearn, and destabilize the normative ways I have learned that one can be non-normative and non-conforming. I am recruiting participants with the hope that 
each and every one will have an image of how they see and understand themselves, whether it is with a label or not.

\section{Critical Race Feminism}

Critical race feminism $(\mathrm{CRF})$ is a framework and movement that serves to provide a more intersectional and comprehensive analysis in comparison to critical race theory (CRT), from which it originates (Wing, 1997). Based largely off of the work of scholar Derrick Bell in the 1970's, CRT itself was CRF's stepping stone in that CRT came out of Critical Legal Studies (CLS), a "radical movement of predominantly white male legal academics that sprang up in the 1970s" (1997, p. 2). Although these academics were supposedly more 'progressive', particularly in critiquing the supposed objectivity and neutrality of the law, progressiveness can only extend so far when it does not include the voices of those most affected and most marginalized by this system - those being racialized people and (white) women. CRT "challenges the ability of conventional legal strategies to deliver social and economic justice” (Wing, 1997, p. 2), states that racism is normalized and deeply entrenched in the very foundations of North American society today, and argues that progress towards racial equity (particularly progress that takes place through civil rights laws) will only go as far as 'white elites' want them to. While CRT is most certainly a step further ahead of CRL in the right direction, CRF takes this stance a step further by centring the voices and experiences unique to racialized women as some of the most marginalized by society and the legal system. With a recognition that lived experiences that are similar but notably different in significant areas of racialized men and white women, CRF does everything that CLS and CRT did and more - CRF also tackled head on systems of racism, sexism, and classism (p. 3). CRF also expands the scope of both its predecessors by including the works of legal scholars and scholars who do not work in the legal system, and incorporating and 
drawing more heavily on the oft forgotten and disregarded area of practice - not just theory (Wing, 1997, p. 5).

In addition to the above named ways in which CRF expands and improves on CRT, CRF also makes explicit prioritization discussions of settler colonialism (with specific regard to Indigenous populations), White supremacy, and Islamophobia. CRF scholars like Sherene Razack, Malinda Smith, and Sunera Thobani challenge systemic oppressions facing racialized and immigrant women, but not at the expense of Indigenous women. In fact, as these scholars state, "Indigenous women were the first to powerfully critique Canada as a white settler society and to analyze its ongoing colonial practices" (Razack, Smith, \& Thobani, 2010, p. 1). CRF scholars do well to implicate racialized and immigrant women, as illustrated by the question they pose, 'How can we theorize our 'place,' when the place itself is stolen? This challenge remains the pre-eminent one for anti-racist feminists as we struggle to understand our own oppression as well as our relatively increased access to social power" (p.2). CRF scholars also do well to challenge Canada's fear-mongering construction of Muslims, "targeting the black and brown bodies of those who 'look like Muslims' for surveillance, expulsion, and abandonment” (p. 7).

My research explores the narratives of LGBTQ+/non-heterosexual East Asian women's experiences in navigating racism, sexism, and classism - as CRF does - but also the systems of compulsory heterosexuality and the Western gender binary. By utilising a lens that takes into account the various complex and nuanced ways in which the participants identify, my research will be able to generate a more comprehensive and holistic approach in better understanding what their experiences entail. 


\section{Chapter 4: Methodology}

The two methodologies that I utilised in this study were intersectionality and narrative analysis. Speaking firstly to intersectionality, I chose this methodology because I felt it would best frame and guide the kind of research I wanted to do - this kind of research being one that took into account the complexities and nuances of people's identities and experiences. The basis of my research at its core, and the kinds of participants I sought, clearly demonstrated to me a need for the use of intersectionality since I was looking specifically at the interlocking/overlapping systems of racism, sexism, and homophobia. In terms of my decision to conduct my research through a narrative analysis, it has always been my aim to engage in each of the participant's individual stories and experiences. I wanted my research to capture and humanize their voices as much as possible, especially given the limitations of an academic paper, and for this reason I thought that narrative analysis would do this most effectively. Something that I had to continuously challenge myself on was not predicting the stories and experiences of the participants based on those of my own, even though I was looking for participants who identified in similar ways to me. The narrative approach (and my own critical reflexivity) also served as a strong and constant reminder to me that every person has their own unique voice and story to tell. I feel that this last piece was what allowed for the narratives that I gathered to be as rich and nuanced as they are, which I will discuss in further detail below under the Findings heading.

At the outset of this research, I developed two primary research questions: 1) What are the experiences of queer East Asian-Canadian women in regards to navigating interlocking systems of racism/sexism/homophobia?, and 2) How did their East Asian cultural backgrounds and values influence the development of their sexual/gender identity? Using a qualitative 
research design, I interviewed two East Asian (specifically Chinese) women who live in Toronto/the Greater Toronto Area through my own personal networks. The eligibility criteria for participation in my study were as follows:

\begin{tabular}{|l|l|}
\hline \multicolumn{1}{|c|}{ INCLUSION CRITERIA } & \multicolumn{1}{|c|}{ EXCLUSION CRITERIA } \\
\hline $\begin{array}{l}\text { Participants will self-identify as women } \\
\text { (including female-to-male transmen, femmes, } \\
\text { nonbinary/gender non-conforming } \\
\text { individuals) }\end{array}$ & $\begin{array}{l}\text { Participants will not be heterosexual- } \\
\text { identified, except in the case of individuals } \\
\text { who are not cis-gender }\end{array}$ \\
\hline $\begin{array}{l}\text { Participants will identify as being LGBTQ or } \\
\text { non-heterosexual }\end{array}$ & $\begin{array}{l}\text { Participants will not be male-identified, } \\
\text { except in the case of FTM (female to male) } \\
\text { trans individuals }\end{array}$ \\
\hline $\begin{array}{l}\text { Participants will be of East Asian ethnic } \\
\text { origin (Chinese, Korean, Japanese, or } \\
\text { Vietnamese) }\end{array}$ & \\
\hline $\begin{array}{l}\text { Participants will, at minimum, be 19 years of } \\
\text { age and older as the research indicates that } \\
\text { this is an age where many individuals will } \\
\text { have come to terms/have time to develop their } \\
\text { sexual/gender identity }\end{array}$ & \\
\hline $\begin{array}{l}\text { Participants will be able to speak and } \\
\text { understand English }\end{array}$ & \\
\hline
\end{tabular}

Each of the one-on-one, semi-structured interviews took about an hour to complete, and were conducted with an interview guide consisting of four sections of open-ended questions (see Appendix A for a copy of the interview guide). With each participant's written and verbal consent, I audio-recorded the interviews for the purpose of transcribing them verbatim (see Appendix B for a blank copy of the consent form). This allowed me to gather quotes, explore critical themes in-depth, and to provide a critical analysis using the two theoretical frameworks that I outlined above. 
Once recording commenced, I formally opened each interview by asking for the participant's age, gender/sex, pronouns, and ethnicity. I asked for their ages in order to better examine the experiences of LGBTQ+/non-heterosexual East Asian women through a contextual lens, understanding that someone at the age of 45 would likely have specific life experiences that a 22 year old might not. Secondly, I asked for gender/sex and pronouns to ensure that I was referring to the participants appropriately in this paper. As well, someone who identifies as nonbinary with they/them pronouns would have different life experiences than a cis-gender woman using she/her pronouns, so it was important for me to hold those experiences with the proper respect and acknowledgement. Both participants identified as cis-gender women and used she/her pronouns. Finally, I asked participants to state their ethnicity. This was important for me to ask because so often in the White-dominated Western world, Asia is depicted under one essentialist brush despite it being comprised of roughly 50 different countries and even more cultures.

Once I met with all of the participants and transcribed the audio recordings, I undertook a process known as 'open-coding of the data' (Khandkar, 2009). I used each of the four sections in my interview guide as themes from which to explore each participant's narratives in more detail. I made extensive notes whilst listening to and transcribing the audio recordings. These will now be discussed in the section below. 


\section{Chapter 5: Findings}

All of the findings discussed in this section are based directly on the two interviews that I conducted with two non-heterosexual/queer-identified East Asian-Canadian women. Both participants were of Chinese ethnic origin and self-identified as cis-gender. They both used she/her pronouns. The first participant, Sasha, was in her early-thirties and did not use a specific label for her sexual orientation. J, the second participant, was in her early-twenties and identified as queer.

Before diving straight into the data, however, I will provide context for how the interviews took place - more specifically, the thematic breakdown. As mentioned previously, my semi-structured interview guide was divided into four sections. The first section asked participants to reflect on what their initial awareness of their "non-normative" identity/ies (in terms of their sexual orientation and/or gender identity) was like. I asked participants to describe what those experiences were like, and to talk about any challenges or barriers that they may have come across. The second section served as a progression of the first by asking participants to discuss what their individual journeys were to exploring/coming to terms with their identity. I asked participants to talk about some of the challenges they faced, as well as any positive or rewarding experiences that they encountered. The second part of this section also inquired about what dating has been like for them. The third section asked participants to speak directly to the intersectional link between culture/ethnicity and queer/non-normative identity. I also wanted to know what the views and values were of their family and broader cultural community, as well as if they had "come out" to them. The last section shifted from cultural community to the broader LGBTQ+ community, what - if any- their experiences had been like in the mainstream and if they felt like there was a space for queer East Asians in it. As a follow-up to that final question, I 
inquired about what alternative spaces that they may have been a part of or what spaces they would want to see/be in.

In addition to discussing the participants' responses, I will incorporate some of my own reflections and experiences. My rationale for doing so is two-fold: 1) I do not want to be an "objective" researcher who engages in research by merely extracting information from participants and studying it as a disembodied entity, and 2) I feel that this method is most reflective of how both interviews actually took place in that they were more conversational than they were one-sided question-and-answer experiences. Although I did my best to be critically reflexive and not take over the interviews by making them about me and my experiences, I made sure that I was open and genuine with the participants whenever I felt was appropriate. This did not eliminate the power dynamic between me and the participant, of course, but I hope that these methods at the very least reduced it.

\section{Initial Awareness of Non-Normative Identity}

The first common thread that I derived from both interviews was that both participants were taught very early on in their lives that in order to be "normal", they had to be heterosexual and conform to the roles and expectations assigned to womanhood. These messages were then further entrenched through religion and religious teachings. As someone who did not grow up with religious influences and did not personally know what it was like to deal with that additional complex layer, I asked each participant if they could elaborate on this experience further. J shared:

It was actually very difficult cause I - so I went to my, my elementary school is a Christian school. No one in my family was Christian. But my mom was like, let me send them there cause I want someone to raise my kids right. And then later, I like actually went to church and then I was in a conservative Chinese Evangelical Baptist Church for 10 years. And then like, so this happens [having her first same-gender attraction in high school], right about in the middle of that 10 years when I was in that church. So 
obviously, like, it's not a great place to come out. Because, you know, in general, people just don't talk about stuff ... One of [the issues within that church] is that nobody cares about each other. So I didn't have anyone to talk to I didn't have anyone that I could relate to. Because just coming from that circle, most of my friends are going to be from that circle as well.

She went on to explain the complex and heavy burden that comes with having to hold multiple parts of oneself at once, made especially difficult when some aspects seem to be diametrically opposed to one another.

So being a Christian, there's a large component of like your relationship with God, and seeing yourself and your identity and then having to hold all of those elements of your identity in like one place and being like, well, somehow, this still should make sense. But how can I make it make sense? Because usually, the idea of Christian also includes straight, cis-gender ... But yeah, so the challenge to me was then, well, how do I hold all of these things together? So I decided to not think about it and just repress this. Yeah.

The idea that Christianity or being Christian is directly correlated with heterosexuality

and gender normativity is one that was also expressed by Sasha.

Okay so growing up, I was always [pause] my own gender identity was more towards the masculine side. So I knew that, probably in elementary school. Grade six was very clear. I always had short hair, dressed like, whatever is defined as like a man or a boy. And I always got teased for it. Uhm, and when I found out that I was not heterosexual was when in university when I realized I liked a girl, which was very - I felt it was not normal, I guess? Growing up in a very conservative, Catholic household.

I did do Bible studies, maybe seven years ago? It doesn't say anywhere where God condemns anyone for being that I can recall for being [pause] that I can recall, for being anything but heterosexual, right. But I learned that growing up that God wants us to have children, so you have to be heterosexual. And that's what I learned growing up that that's why you cannot be homosexual, right, because you need to reproduce. And that's the purpose of life.

Both participants also identified their respective churches as being unsafe spaces not only to be openly queer, but to be queer to oneself as well. Despite Sasha noting that nonheterosexuality was not specifically condemned in the Bible, anti-queer sentiments were frequently espoused and reinforced in these settings. Although these messages can sometimes be 
subliminal or indirect, there was one incident that $\mathrm{J}$ reflected on which made it clear to her that

homosexuality/queerness was not acceptable or even possible.

I was in a high school fellowship in my church, and we had this one counselor who was like, "You guys can talk to me about anything!". And I was like, "Okay, well [laughing], I'm about to go for this cause uh, I need help and I am at my wit's end. I need to find someone to talk to. So I talked to her. And initial - essentially, what she says is like, "But [drawing out J's name] JJJJJ" - see, there it is - "But J, don't worry, like, a lot of gay people end up marrying straight people anyway, so it's fine". And I was like [making a noise], I just took the last year realizing that like, marriage is not like the best thing of life. And it's not like, the greatest joy, and you just brought it all back. So that was exceedingly unhelpful. And on top of that, she followed it up with something like, "Well, what do you have any questions? And I was like, "Yeah, I'm just like, not sure what the Bible is saying. And I don't know, like what God's saying either". And she's like, "Well, I can tell you what they're both saying. This is what it is, which is essentially like, yeah, God doesn't want you to be in like any kind of same gender relationship". And I was like [exasperated sigh], you as a person with like, zero, zero like, investment in like this. And like, if this were a soccer game, you're just permanently sitting on a bench. Like you, you said that really fast. And you said that like very non-consequentially. I don't think you understand, like, how difficult this is. [speaking about confronting the counsellor a year later] She didn't remember saying that to me. Can you believe it? Yeah. So that that was like an active barrier to me wanting to seek help or to seek any kind of resource because, like, why would I want to do that when this is the result?

Another common theme from both participants' stories was that they learned and/or were

forced to repress this part of themselves. Sasha recounted a specific period in her life when she repressed her sexuality:

For university, I remember I internalized what it meant to be anything but heterosexual. So I knew how to demonstrate what heterosexual looked like. So I would talk about boys, you know, just to fit in. Uhm, I worked at [a store in downtown Toronto], where a lot of people identified as non-heterosexual. So I took-I guess I took-like I know I had a lot of gay friends in [the store]. So I hung around with them a lot. I went to gay clubs and things like that where I would drink, get drunk, and pretend. Like I would tell them "Oh, yeah, when I get drunk, I am a lesbian". Right? Even though that's how I felt like I identified. I didn't want people to know that. Because of - I don't know, if it's being East Asian as well, in my culture, my religion. But I didn't want people to know so I made that as an excuse.

J discussed how in her formative years, repression "made things significantly worse".

Because then like, you know, being, being in high school, school, it's tough. And then when I got to grade 12, so this happened when I was in like, grade 9 to 10. So when I got 
to grade 12, like, I saw this other girl, and I was like, "Oh, my gosh, she's so cute". And she was in my art class. And then like, things progressed, and like, we're almost in this like, weird relationship thing. And I was like, shoot, now I actually have to, like, make some kind of decision. Like, it's so real now. It's not just like, like a theory or like a thing I kind of just know about myself. Like, it's having real world repercussions. Yeah, so that year was awful. That was like when I actually came out to myself, because before I was like, "I'm just not gonna think about it". But then when I actually came out to myself, and it was like this huge identity crisis, this huge thing of like, "Uh, can I still go to church? Does God still love me? Like, uhh, I don't know any of these things. And I was, I was like ... in air cadets. And like, things were were weird there too. And I started like, filling up all my time with like, all these activities that weren't school. And as a result, my marks were really crappy, and I had to do a victory lap. And then I also just, I don't know, everything just kept falling through. So eventually, I was like, depressed for the entire year. And I don't know if it was like a brain chemical thing, maybe I'll never know. But it was definitely a situation thing. Because like, all of these things, just all compacted together. And like, I'm like, this little high school kid who doesn't know how to, like, doesn't know how to care for myself, doesn't know how to cope. I have like zero, zero healthy coping techniques. And nobody's helping me. I don't know where to reach out. So yeah, it was a bad situation. That was what it was like, when I was initially coming out to myself. And then in that year, I came out like the first person on MSN [laughs].

Hearing from both participants that they used repression as a means to deal with their sexuality resonated with me as a queer person who has done exactly that for much of my life. It made clear sense to me that they would fight and hide this part of themselves in order to survive in a world that otherwise would condemn them for not being heterosexual.

Exploring/Coming to Terms with Identity

Sasha spoke about contending with internalized shame, which had been exacerbated by

comments that her friends would make towards her.

So it's been really difficult to hide who I am even with family and friends who don't understand. Like I've had friends who said, you know, I wasn't ... fully ... you know, I was homosexual, where they would make comments like, "You can't - don't like me. I know you like girls. You know, you - don't like me cause I don't go that way”, or whatever they say. And it kind of shuts me down. One of my best friends said that. I remember, she's like, Yeah, I know you like girls. And I've never told her I did. I guess she sensed it. So it's been really tough dating because relationships never lasted so long because of the shame I had and the shame I sensed - that society has. 
For many queer/non-heterosexual people, it is a common experience to have heterosexual people make comments like these that reinforce stereotypical notions of homosexuality as being inherently predatory. It goes without saying that these comments are difficult to hear from anyone, but the consequences are often ten-fold when they come from people who we know and love. As Sasha already spoke about, these harmful beliefs create or increase the sense of shame that one might already feel from not being "normal".

Luckily, however, love and support can and do actually exist for queer/non-heterosexual people. $\mathrm{J}$ shared about having a rewarding experience in exploring and coming to terms with her sexual orientation.

[on joining a small group catered towards LGBTQ+ Christians] ... that was like a big benefit because all of a sudden, I had people to talk to, I had community, I had people who love me, people who are willing to answer my questions. And like, just generally not feeling alone is pretty great. And eventually, they - I finished their programs. They do it in cohorts, there's like twelve weeks. And then, like, at the end, they're like, "Hey, do you want to volunteer?". And I was like, "Heck, yeah". So I did that. And it was really great. Because each cohort is just about like discussion. There's no real intention in like moving anyone to any place. It's just, we know that this is something that people want to talk about, and you talk about it, it feels better, it helps things be less bottled up, because it's just not healthy when you do that. So that was great. I got to volunteer with them. And I made a lot of great friends. And even now when I'm not doing anything for them anymore, I still have these friends and like they're really wonderful people. So that was like a big reward. And I wouldn't have been able to know any of these people if it hadn't for me being gaayyy, and then like joining this, and then here I am. And other than that, like there's other babies in my church that I love that I have later found out [laughing]. And like, they're not out in church, but when they know that I am so they can talk to me, and I know about them. So it's just really sweet being able to make that connection cause it's not, it's not a safe place.

It seems to go without saying, but it is clear from J's narrative that having a safe, supportive, and accepting environment such as the one she found in this particular group was a very helpful and positive experience. In the last part of that quote, J mentioned briefly "babies" in her church who were not out but knew that they could access her for support. This part struck 
me right after she said it, and I responded by saying "So you're basically the person for them that you didn't have when you were in their shoes". What followed this comment was a mixture of laughter, hesitation, and acceptance (albeit reluctant) about the importance of her role in these young queer peoples' lives: "Yeah, maybe. I feel like I'm slowly working towards it. Yeah, so that's a big reward for me. It's just the best thing".

A rewarding part of Sasha's journey was similar to J's. Because she does not identify as heterosexual, she spoke about being able to have a more in-depth understanding of the oppression that non-heterosexual people face, thus she has been able to unlearn much of what she was taught growing up. This on-going process, as she will describe below, has allowed for her to both have teaching moments with her son when he expresses anti-queer sentiments that he has learned, and also to let him know that she will love and accept him exactly as he is.

What the reward is, is how my outlook on society and how I didn't-cause when I was younger, I would perpetuate what it meant to be normal. So I did the - you know - I shamefully admit that I did - I guess I was homophobic growing up to fit into the norm with my friends too, right. When they make comments I joined in so that they wouldn't know I was not, I guess, quote-unquote "normal". So now that I know and I'm not like - I am more aware of who I am and what society, like why society says I can't be. So that helps me like when I'm supporting others. It helps me not place labels on people and really understand where each person is coming from, including their intersectionality, as well as, you know, wh, with my son, for my son, they didn't teach him about diversity. As much as I can, like it's not fully diverse. I teach him about different genders. I showed him DVDs from National Geographic about, uh, gender identity, what different types of genders, different types of relationships, different types of sexual orientation. So all those different - I tell him it's okay, right, and I'm fully supportive and I teach him that when he comes home with homophobic comments that he learned from class, you know, I can correct him.

...to have that kind of openness, so in case in the future, let's say in the future he wants to identify as part of the community. He knows I'm accepting, like, he doesn't have to come to me and be like, "Hey, mom, I'm coming out of the closet". He can just be like, "Here's my boyfriend" and I'm like, "Okay. Come! Welcome!" 
Of course, as has already been discussed extensively in the pages above, being a queer/non-heterosexual person in a heterosexist society presents a variety of challenges - one challenge in particular is navigating the world while being in an openly queer romantic relationship. J, who spoke about being involved in the group for LGBTQ+ Christians met her current partner there, and described that experience as follows:

Purity culture is like beyond - it's just like, a general way that we like talk about things. So like, in general, we're telling the girls like "You guys need to cover up and you're a stumbling block. And we're telling the boys like, basically nothing. "Don't touch yourself. Don't watch the porn" [laughing]. Yeah, and it's like, it's like, there's always this um, built up thing where it's like, [doing a voice] "It's a man and a woman". Yes. So when all of a sudden I'm dating a [pauses for emphasis] woman, it's like, what happens now? And then on top of that you have uhh, they teach you about marriage. And it's like, there's the role for the woman. And then there's the role for the man. And now I'm dating a woman [laughs]. And like, do I even think that there are specified, like, gender roles that are actually legitimately described in the Bible? That's a totally different conversation, whether or not that's true. But anyway, like that, like, none of this is what I expected when I was growing up. Like, this is not what I was told was going to happen. Yeah, so it was very strange. And on top of that, I hadn't thought about dating for at least two, two or three years, cause I was like, "Well, I'm gay. So guess it's never gonna happen". Yeah, so when all of a sudden I started dating, I was like "Wait, what?"

Yeah, so, I was just like, reeeally confuuuseddd. Like, what happens now? What's different, cause it feels like pretty much the same. Aside from the fact that like, now we're actively like, making enemies. Cause like, now that you make it like official, like you use the term 'dating', 'we're in a relationship', 'this is my girlfriend', like, all of a sudden, you have placed yourself in a certain category for [pause], for certain people, some of them being my friends and my church. They now see me as like maybe a threat or maybe like, uh, someone that they should be careful around. Do they still want me around their youth? Am I going to like, lead them astray with like, this? I, I don't know. So as much as it is, like a great thing, it's also like, uh, it's almost like uh, I'm not burning bridges, but I'm certainly like jumping on them. Cause like, now I'm shaking how other people may perceive me or their placement of me in their categories in their mind.

Similarly to the messages that Sasha expressed above, J was also a recipient of these harmful, homophobic, and completely unfounded notions that queer/non-heterosexual people are inherently amoral, predatory, and dangerous. I expressed to $\mathrm{J}$ in our interview that from my perspective, heterosexual and/or religious people will "tolerate" your queerness only if it is in 
theory and not in practice. So often I have heard from heterosexual people that they would accept our "lifestyles" if only we did not "shove it in people's faces". As J stated, people began to treat her differently once she had "solidified" her queerness in the form of a same-gender relationship. In this way, people like the counsellor she spoke with could no longer hope or believe that she would just end up in a heterosexual relationship.

Influence of Cultural Values/Expectations

As Crenshaw’s (1989) intersectionality theory would have it, no one person goes about the world operating based on only one part of their overall identity. The participants, then, are never just women or just East Asian. They are queer/non-heterosexual-identified, cis-gender, East Asian women all at the same time in any and every part of their lives. Thus, it was important for me to include this particular section because being racialized adds an additional unique layer to what are already complex identities as queer/non-heterosexual women. As I discussed in the Introduction, I have spent my entire life learning and understanding what it was like to grow up as a queer Chinese-Canadian woman. With this research, however, I wanted to know what other people's narratives were since my experience is only my own.

When I asked Sasha what her experience was like with specific regard to her cultural/ethnic identity, she said this:

I don't fit the norm of my culture for me to even consider - I feel like there's a hierarchy. Uhm, so what I know from my own personal experience of my cultural identity, and what that means is, first of all, I have a child, and I'm a single mother, and that defies everything my culture stands for because it's a heterosexual man, woman married, right? I was never married. The nuclear family - didn't have that. [speaking about not being able to demonstrate filial piety to her parents] Like I can't even do that, and then for me to even come to them and be like, "Hey, Mom, and Dad, I want to talk to you about .... my sexual orientation". That's like, the most terrifying thing for me. Like, they already ostracized me when I was pregnant with, like, without getting married, that was the scariest thing too ... But now, I don't think that's something my parents can handle, or even if they hear me say it, I don't think that it's something that they would accept. 
I feel like I defy a lot of the cultural norms in a Chinese family. And a lot of them you can't hide. Your education, which university you go to - you can't hide those. But sexual orientation, you can hide ... and that's why I dress more feminine now ... [laughs, pauses] so I can fit into the norm.

One key part of what she spoke about was the Confucian ideal of filial piety. Confucius was a Chinese philosopher whose teachings and ideas have been an integral part of Chinese society since the $6^{\text {th }}$ century (Cartwright, 2012). Here is one explanation of what this traditional Confucian Chinese ideology is:

Parents gave life to children, gave them food and clothes, an education, etc. For all the things that children received from parents, children have an eternal obligation towards them. They have a debt towards their parents, a debt that can never be fully repaid. The only thing that children can do in order to repay at least a small part of this debt, is to take care of their parents in their old age, to make them proud and happy, to obey and serve them. (Teon, 2019)

Another important facet of Confucianism is interdependence. Unlike in Western society, one's self-identity is deeply embedded in a group identity, so to be 'non-normative' - in the case of Sasha, to not be heterosexual, to have a child out of wedlock - would be seen as a transgression of the group's overall harmony (You, 1997). Thus, the feelings of shame and guilt which have already manifested from being non-heterosexual-identified in a heterosexist society is exacerbated by the cultural belief that she has dishonoured her parents.

$\mathrm{J}$ also made mention of filial piety when I asked her the same question.

So in church, obviously, most people are homophobic, and there's different ways they could be homophobic, it can be like, homophobic, and then like, like, in a very active hating sort of way, like you repulse me, or could be homophobic in the way of like, I think you're living wrong. And I'll still kind of be civil with you. So there's that. And does that have to do with them being Asian? Or is it just them being Christian? I think it's both because uhm, they, there's a certain way to present the Bible in the Gospel that has like Chinese influences in it. It's filtered through a cultural lens, and anyone that tells you that it isn't, is - they're honestly, just blind to it. It's impossible to not notice if you compare, like Chinese literature about, like Christianity, compared to Western English literature about Christianity, like there was a stark difference. [I asked her to provide an example] Uh yeah, so a very popular thing for Christian, Christians who are Chinese to do is to like, add that little bit of Confucianism in it. So let's say the value of like honoring 
your father and mother, filial piety, they'll connect that to a verse in like, Romans, per se, that's like, uhm, if you honor your mother, like something good about respect .... it's like, if you if you like, Honour your father, or your mother, most likely father it says, then you'll like live a good life. And then they'll connect that back to Chinese value. And whether or not they're doing that, like expressly is like, is not important, because it's just the way they talk about it. You can tell the difference.

[on overall Chinese culture, Confucianism] I guess it really sums down to my parents, because I am a representative of my parents. And I am supposed to carry on the legacy of my parents. And essentially, me being gay is like, I'm kind of a disappointment, cause I'm not going to marry a man. I'm not going to have like, a very lovely Chinese wedding at like a restaurant. But like, I'm just not going to fulfill that dream of like, continuing to carry a last name, or have necessarily grandchildren the way they thought I'd have grandchildren, you know? So it's like, almost a feeling of disappointment. But that could be my projection. But I'm quite certain that if I were to come out to my family, same thing, like extended family, that this would be the general attitude, because all of my cousins are married with grandkids or with kids now, and it's always met with such excitement and joy, that I can't see how like me being like, "Hello, meet my girlfriend" would be like "Oh, yeah, congratulations". Yeah. So it just boils down to like, it's not a positive thing. It's not we're not celebrating. We're just going to merely like, try to be okay with it.

Despite experiencing the heavy influence of these Confucian ideals from her church and

her extended family, $\mathrm{J}$ did share a narrative that, in the moment and even now long after has been

over, I was personally shocked to hear due to my own assumptions of East Asian families and homosexuality.

But uhm, so for so for my mom. She's actually a very interesting person because uh she's not - so as many people think, that this isn't just like me saying like my mom's special. This is other people also telling me this, is that my mom's quite different. So when she was coming to Toronto, initially, she went for an organization that taught Chinese parents how to talk to their kids about sex. [responding to my surprised reaction] Yeah, I know, right? And then she, like started doing workshops and stuff and now she works with seniors. So when I was coming out to her, uh, it was actually a really [pauses] good experience, because she wasn't like, she wasn't like immediately like, "Oh, this can't be, like you cannot be this". Instead, she was like, "Oh, okay, well, all right. And ... Actually, if you want to know the entire thing, I actually brought her to the last night of the small group thing that I was going to on the Christmas party, because like, she was driving me and it was a giant snowstorm. And then I was like, I can't tell my mom to drive back two hours in this giant snowstorm. So like, I called up and I was like, "Can I bring my mom?" Like, yeah, so I mom came up, met all my queer friends. And like, it was great. 
And then later, when we were driving home that night, she was like, "Sooo" and I was like, "Yeeaahh".

But the biggest thing was that she knew that there were people that were caring for me. And not only was it like, I knew that I could tell it to her, like with my mouth, but I knew that she wouldn't have believed me, but she was able to go in and experience it for herself. So for me, I believe that God had a hand in orchestrating this and really convincing my mom that I was indeed Okay, and had people caring for me. And then later, I did this like thing at church, one of my friends was doing a Sunday school class, and they were like, talking about the gay people again, and like, a lot of people had a lot of things to say, like, I was like, absolutely not, I will not be having this. So I told them, actually, if you want, I can tell these people about my testimony, which is basically my story about being gay and Christian, cause I don't want them to talk about it like all the gay people are outside, because guess what, I'm here. And also, there's probably other people who are here and queer. So we should be cognizant of that. And then later, when I did that, I was like, crap, I just came out to my church. So then I told my mom like this happened, just in case someone came back to her was like, "Hey, I heard your daughter...". And she was the, her first concern was, "Are the pastors treating you differently?" Yeah. And I was, like, just super touched, because that was what she was the most worried about, that somehow I'd be treated differently. So that was a really positive experience.... She's the great, greatest mom. And I cannot like thank her enough for just being like, defying all expectations.

It is just as, if not more important, to make known that experiences like these are real and do happen. My assumption going in to this research and these interviews was that the participants were going to have parents and/or family that were unaccepting and unforgiving of their sexual orientation because of what my personal experience had been and what the dominant societal narrative is. The dominant narrative I am referring to is the one that says that racialized parents - East Asian parents, in this case - would unanimously be intolerant and homophobic. What $\mathbf{J}$ shared is a powerful counternarrative to what is an essentialist, problematic, and even racist belief that many of us who are racialized have internalized. It is so imperative that these stories do not go untold and/or unheard.

Perspectives on the Mainstream LGBTQ+ Community 
With this final section, I hoped to gather what each of these participants' experiences (if any) had been like beyond just their families and/or communities. I wanted to know both what it had been like for them as queer/non-heterosexual East Asian women in the larger, mainstream, White male dominated LGBTQ+ community. I also inquired about whether or not they felt like there was a space for queer East Asians in the community, about carved-out spaces that they had been or were a part of, and what kind of spaces they would like to see more of.

Both participants had comments to make about how the LGBTQ+ community is represented/discussed in the media, and particularly in terms of the campaigns surrounding Pride. $\mathrm{J}$ made an observation about the specific language that is commonly used in these advertisements:

Have you noticed how all the queer advertising or like all the LGBT Pride advertising campaigns it's always about love? It's never said like, specifically, like gay. It's always like, "Love all". "Love is love". "Love everyone". And like "unity"? It's so weird. Yeah, it's like nobody actually wants to say like, "gay, lesbian, bisexual". Like, apparently those aren't like, sellable words.

Sasha remarked on the specific kinds of people who were often featured in these ads: It's predominantly, it's predominantly white. If you look at the Pride flyer, it's two white girls. It's always white. Like, I don't see, let's say, two Chinese people together on a flyer. I feel like it's mostly white and a lot of people I feel like, a lot of white folks can come out, quote-unquote, I feel like they're more comfortable. I feel like Canada wants you to come out and be all accepting [laughs].

This last comment touched on what it means and what it looks like to be queer/non-

heterosexual in a White, western, Canadian context. She elaborated on this further:

Ifeel like there's this pressure - in society, there's this pressure - like it's okay, just do it. Everyone else is doing it. Right? What are you ashamed of? Like there's that part, but they don't look at the violence and the cultural meaning for me. Well for myself, what does it mean as a Chinese person coming out?

Again, this touches on Chinese Confucian ideals that emphasize the value of the group over the individual. Each person is a reflection and representation of their family and 
community. This idea that one "comes out" is a concept of the Western world which emphasizes the individual's being without much relation to the community. To reiterate the previously-made point by You (1997), the notion of "coming out" would be seen as a transgressive act that would disturb the harmony of the whole. Many of the messages propagated in the Western world are ones that have no cultural sensitivity or awareness of, as this participant said, what it would mean to "come out" as a racialized person. There is a different kind of shame that is instilled through LGBTQ+ movements if you do not go through this process and outwardly show the world how "loud and proud" you are. This was demonstrated by her stating, "What are you ashamed of?" it is a shaming of the shame one already feels.

In regards to Sasha's personal experience of what it was like when she was in a samegender relationship, she said:

I, I don't know what it is, I feel like mostly it's the white population that get angry [pause] that put me in my place. That opens their mouths. Like they're the ones that would say "You're gross", you know, they're they're the ones that come up to me, like the East Asian - the Chinese folks, when they see me, whether with a racialized person that I'm dating, or someone of the same sex - they look, they don't look happy, but they mind their own business and they go. But the white folks that will come up to you and say things in your face, and make you feel like [pause] abnormal and disgusting. Yeah. That's my experience. I don't, I don't want to generalize this to all white folks, but that's what I've experienced. But it's really helped me - what helped me try to be normal, cause I don't want to be called out. I don't wanna be anything but normal.

When I asked the $\mathrm{J}$ the same question, this is what she had to say about her own experiences:

Okay, yeah. So I've only been in the mainstream for maybe a year to like a year and a half. Because, so I stopped going to the church that I was talking about, like, maybe - so this past April marked officially one year. So like that, that wasn't, that wasn't like a long time ago. Like that transition was actually very recent. So immediately after that happening, I was I was going to [an LGBTQ+ Christian space]. And [the LGBTQ+ Christian space] is interesting, because they have, like a huge age range, like university students to like, we're almost going to get retired. So that was a positive because like, cool, I've never seen anyone that is like me, that has made it that far. All of the people 
that I know, that are queer are like 20. And like, we're all struggling to get through university. And like, find jobs, like to meet some that was like, "Yeah, I came out like 20 years ago. And now I'm like, saving for my retirement. We just bought like two rabbits". Stuff like that. It's like, just really hopeful, because it's like, you continue to flourish, there's actually a future for you. Like you can it's like one thing to know it in your head. But another thing to see it in real life. Yeah. So that was really positive. But again, it's a very white space. So if I said to them, like, I go, I went to a queer-I mean, I went to a Evangelical Baptist Chinese church, like that means nothing to them, they have no idea what it means to go to a Chinese church. And that, to me was like shocking, because I was like, wait, what do you mean, you don't know? Yeah. So not only is that like, it means that they not only don't understand, like, where I'm coming from it in my like spiritual life. But it also means they don't understand where I'm coming from, like in terms of my family, my community, like what kind of values have been ingrained in me as I'm growing up, like, none of those things. So it felt like, uh, pretty, pretty .... tiring, because I have to constantly explain myself, I have to constantly like, give like context and background and like, explain, and like. So when I join group conversations, I tend to watch listen first before I jump in, just sometimes like I find more value in the listening part because like, I don't really have anything important to say, but then it makes me wonder, "Am I just like being my stereotype of like, the quiet Asian girl?".

It is important to acknowledge that $\mathbf{J}$ has had positive experiences being in the broader LGBTQ+ community, and for her, it was a space that allowed her to hold her queerness and her faith. It is also important to recognize, however, that Whiteness still permeated throughout. She was constantly reminded, although not maliciously, that she was racialized in addition to being a queer person. She also highlighted a specific area within the broader LGBTQ+ community that is also White-centered:

[discussing a book she was reading about mainstream queer archives] So the story, the book is about a criticism of how people have archived things, where they use, like the, the people of color, who are also queer, as kind of like a sprinkling of tokens inside their archives. And it's never like, they never, they always speak of the white queers as like, they're like, the forefathers of this movement. They're the ones making the real moves and the real changes. And like these, these people of color queers, like they, they're just following along. They are not making any like unique moves of their own. They're not making any real activism of their own. That's all false.

After really taking in and processing her words, I started to think about how the people who have the most power and privilege in society - in this case, White Europeans - are often the 
ones who get to write the history books. And if these are the people that are creating historical and present-day narratives, then these would be the experiences that would be heard and known by society at large. Then, as this participant stated, the very presence of those who are Black, Indigenous, and racialized are pushed to the side as afterthoughts (if they are thought of at all). In response to the second part of the question, Sasha responded back to me with a question of her own:

But why do we need a space? Like why can't everything be a space? Why do I need to - I feel like we're trying to create a small space. Right? Why can't it just be any space that we occupy? Why do we have to segregate ... and go to a remote location where we can come together and feel safe together? Why can't it be anywhere I go, I feel safe and accepted for who I am. Right? So we're trying to create these spaces, which are pretty isolated from what normal is, because now we have to identify like, I don't know. I feel like it's counter-productive.

This is a very fair and valid point, and I could see where she was coming from.

LGBTQ+/non-heterosexual people are already marginalized and ostracized enough as it is, so creating a separate space would only serve to reinforce the status quo instead of challenging it. LGBTQ+/non-heterosexual people should have access to a safe space in every space, not just the ones made specifically for us. Knowing and understanding what she meant, I still wanted to know what kind of space she would envision that she would feel safe and want to be in. Since we both identified that the world we both currently occupied was not a safe space to be in, nor was the broader LGBTQ+ community, what would this idealistic space look like?

Okay, so yeah, so I guess a space where, yes, with racialized folks. And folks who understand intersectionality, especially with race, the impacts of colonialism and whiteness, and impacts of our - like even with being Chinese right, or any - South Asian - whatever the race is, about the impact and how it's different from white folks. Right. And about our culture, and what's the - how that's different from white folks. People who work in that space or who are in that space to understand all those intersections, even to which gender we identify as ... Like all the intersections, to have that space where people understand [pause] the nuances - like the complexity of multiple identities. 
In response to my specific question around if she knew any spaces that existed

specifically for queer East Asians, J responded with:

Are there spaces? I mean, I assume there are. But even the idea of having a space is kind of foreign to me, because, so I know that there's like brick and mortar style places for like, uh queer LGBTQ+ queer men. Like, gay men. Like they have like actual establishments that are like physical spaces, right? But then like, for [the group she is involved with that serves LGBTQ+ East and South Asian women and non-binary folks], we're always just like, we meet up where we can afford it. And I don't know, like holding space for something is so conceptual. And I, I want to believe that there is a space for and that [the group she is involved in] is creating space.

Her response touched on an on-going issue that has disproportionately affected

LGBTQ+/non-heterosexual women and non-binary folks. She identified that the physical spaces she knew of were predominantly catered towards LGBTQ+/non-heterosexual men, which demonstrates that issues of patriarchy and male-privilege are rampant in the broader community as well. In addition to the specific group that she is a part of, she named a few others that she knew of that shared a similar specific target population.

So I know that those could be also considered spaces where people could feel a sense of belonging and feel a sense of like, I'm in the majority here. But again, like they don't have an actual, like, concrete space. Like, it's like we meet here, we meet there. Maybe they have an office? I don't know. But it's not like a physical space, which I think is different. Yeah, and I want to believe that there's possibility for that in the future, but it makes... I don't have a huge amount of hope for it. Because I just, I, it's so difficult having a space, you have to pay rent, you have to pay the electricity bill, like, that's a lot of money. And like, when your community is like, already on, like a part of the spectrum where you're, you tend to not make that much money, like how are you going to fund that kind of space? And I'm like .... I don't know.

Although dominant societal narratives and media representations would say otherwise,

both of these participants clearly demonstrated the unique, complex, and multifaceted experience that comprises being a queer/non-heterosexual East Asian woman. In the first section of my interview guide, some of the common themes were that participants grew up learning through a variety of sources that they had to be heterosexual, and then struggling immensely within 
themselves to reconcile their queerness/non-heterosexuality (which took the form of depression, repression, etc.). In the second section, both participants identified similar barriers that they encountered in their journeys to explore/come to terms with their identities, such as dealing with harmful and unsupportive responses from the people in their lives and struggling to unlearn the internalized homophobia that they had been taught growing up. On the flip side, they both also identified positive and rewarding experiences that they had encountered. In the third section, both participants spoke about the influence that Chinese Confucian values and expectations had in how they navigated their identities, and specifically the way that filial piety shaped their decisions to be open with their parents/family. The last section brought up themes such as the many pervasive systemic issues in the mainstream LGBTQ+ community (patriarchy, Whiteness) and the complex nature of having specific spaces for queer East Asians in that, while it is necessary for a safe space that the broader community does not offer, finding space can also serve to further marginalize people who are already marginalized. 


\section{Chapter 6: Discussion \& Analysis}

This next chapter will provide an analysis of the data in reference to the Literature Review section and to the two theoretical frameworks discussed previously, queer theory and critical race feminism. I will conclude by discussing some of the limitations of this study, and provide some recommendations for future study in this particular area.

The topics that both participants addressed in the first section of the interview align directly with what much of the literature has also found. Both participants grew up in highly religious environments that did not support or accept their queerness/non-heterosexuality, which is reflective of the findings by Logan \& Buchanan (2008). The two participants they interviewed that shared similar religious upbringings dealt with the same feelings of guilt and shame because homosexuality was constructed as wrong, sinful, and contradictory to their faith. They also turned to repressing their same-sex attractions, as the participants in my study discussed, which were emotionally and mentally taxing. Anti-LGBTQ+ values and beliefs have a long and complex history that is deeply intertwined with British colonialism, White supremacy, and Christianity. As Han \& O’Mahoney (2014) state, “...through its colonial administration, the British managed to impose and institutionalize a set of legal codes in its colonies that criminalized homosexual conduct", which served as well to 'protect' Christian "soldiers and colonial administrators ... from 'corruption' as well as correcting and Christianizing 'native' custom" (p. 273). From considering both the narratives of J and Sasha, as well as factoring in the pervasive anti-queer narratives still being espoused by faith institutions and broader Canadian society, it is clear that these colonial legacies have continued to persist to the present day. Being reminded constantly that something about you is inherently wrong and shameful will most likely have negative consequences for one's health and well-being, as both J and Sasha remarked upon. 
This coincides with Nadal et al.'s (2011) research, which found that participants who were under constant emotional duress from anti-LGBT sentiments often developed mental health conditions like depression and anxiety. This can be seen in the part of J's narrative where she spoke about first coming out to herself, avoiding and repressing this knowledge, having other things in her life fall through, and then suffering from depression as a result of all of it.

In the spaces that $\mathrm{J}$ and Sasha identified (religious, familial, societal, community), it appears that there was no room to trouble or question sexual identity categories such as straight and gay. The messages that were received by both participants were that to be heterosexual is to also be normal, moral, safe, and right - to which anything but heterosexuality is deemed abnormal, amoral, dangerous, and wrong. It goes without saying that this categorization of sexual orientation is harmful and erroneous, but it is also troubling because human sexuality in this light is understood only in stereotypical and binaristic terms. Earlier in the Theoretical Frameworks section, I mentioned a quote by MacKinnon (2010) which stated that: “...queer theory pries open discussions of sexual subjectivities, implicating everyone in the conversation, to make teaching and learning about sexual difference inclusive, fluid, and complicated. As messy as sex" (p. 3). What both Sasha and J were taught, however, made no space for the inclusive, fluid, and complicated learning/understanding about human sexuality that queer theory espouses. When I asked Sasha early on in our interview how she would label her sexuality, she responded that she did not use one (and nor did she want to). Although not intentionally, she pushed me to think about how I was reinforcing these rigid, check-box type of categories onto her so that $I$ could feel more comfortable in how to respond to her based on which box she checked in my mind. As she elaborated further upon, this is also what LGBTQ+ movements in the West have predominantly looked like - a loud and bold embracing of whichever letter one 
has chose to identify with from the LGBTQ+ acronym. I think that Sasha's decision to not use a label embodies exactly what queer theory pushes for, which is a more complex and nuanced way of thinking about sexual orientation beyond labels and definitions.

The other theoretical framework that I utilized for this study was critical race feminism. With specific regard to the voices and experiences of racialized women, the work of CRF scholars use an intersectional lens to address systems of oppression such as racism, sexism, heterosexism, colonialism, and White supremacy. Similar to queer theory, CRF also pushes for more complex and nuanced ways of thinking. One example of this was J's positive and supportive experience in coming out to her mom, which challenged my own pre-conceived expectations of what process was going to look like. By undertaking CRF's primary goal in centring the voices of racialized (in this case, Chinese) women, we were able to see first hand a counternarrative that challenges and disrupts dominant narratives that would be unlikely to acknowledge important stories like these.

It was also of imperative that these narratives be understood through an intersectional lens that acknowledged all of the various ways in which queer/non-heterosexual East Asian women have experienced, interpreted, and dealt with multiple systems of oppression. One of the central findings from the data was that coming up against these systems forced both participants to struggle in holding and accepting all parts of themselves at once. The participants in Park (1997) and Chan's (1989) studies expressed similar challenges as well. In Park's study, participants identified difficulty in synthesizing their identities as East Asian and Canadian due to systemic and internalized racism. The lesbian and gay Asian participants in Chan's study felt that their sexual minority identities were diametrically opposed to their cultural/ethnic identities. The two participants in this study struggled to navigate being Christian/Catholic, East Asian, and 
queer/non-heterosexual when it felt like both their religions and cultures did not allow for the latter to even be a possibility. This can be seen when J expressed the challenge in, "having to hold all of those elements of your identity in like one place and being like, well, somehow, this still should make sense. But how can I make it make sense?”.

The interlocking issues of White supremacy, racism, and sexism all came up in the last section when I asked participants to share their thoughts on the broader LGBTQ+ community and whether or not they felt like there was a space for queer/non-heterosexual East Asian women in it. Both made mention of the pervasive Whiteness that operates throughout the community, which is an interesting point of discussion because within marginalized groups, there still exist hierarchical structures that are reflective of societal structures as a whole. It is typically ablebodied, cis-gender, White, gay males who possess the most privilege and visibility, while those who are afforded the least privilege and visibility are most often dis-abled, transgender, Black/Indigenous/racialized, queer/non-heterosexual women. Although J had a positive experience in joining the LGBTQ+ Christian group, the membership was predominantly White and so she was constantly cognizant of the fact that she was not. In this way, she occupied a position as both an insider and an outsider. Sasha's experience of being in a public same-gender relationship garnered homophobic responses from White people that have been violent explicitly and directly.

Taking into account all of the above, it is no mystery then that racialized (especially those who are Black and/or Indigenous) women are amongst the most marginalized people in nearly every facet of society. When you add in other factors such as sexual orientation, class, gender identity, dis/ability, religion, citizenship status, etc., the levels and complexity of marginalization can become exacerbated. 


\section{Limitations/Suggestions for Future Directions}

Some of the more obvious limitations to this study were that only two participants were interviewed in this study. Although the narratives of these two participants are extremely important and are enough just as they are, perhaps future studies could ensure that a wider range of voices and experiences be heard. Another suggestion for future studies is that the participants be from a wide range of East Asian backgrounds. The limitation with my study was that both participants (and the author) were Chinese, so the experiences shared highlight the stories and experiences of two individuals from this specific racial group. If I had more time (another limitation), I would have strived to recruit participants from Korea, Japan, and Vietnam as well. In my opinion, one of the most significant limitations to this study was that none of the participants were transgender or non-binary. Trans and non-binary voices, particularly belonging to women/femmes, are amongst the most marginalized and neglected groups. Hopefully future research can be sure to not only include these voices, but to centre them. 


\section{Chapter 7: Conclusion}

As a queer East Asian woman who grew up with little to no knowledge or awareness of others like me, I embarked on this research because I wanted to know what the experiences and stories were like of other queer/non-heterosexual East Asian women were. As I discussed in the Introduction, I did not know anyone else's story but mine, and I also wanted to gain some sense of belonging. Another reason I chose to focus on this specific group was that I did not see us reflected anywhere in all of the academia I encountered. So much of the Western world operates on a Black-White dichotomy that often neglects those of us who are neither. I hope that my research, small and rife with its limitations as it may be, can contribute some part to alleviate this gaping hole.

The two primary research questions that framed this study sought to understand what some queer/non-heterosexual East Asian-Canadian women's experiences were in navigating racism/sexism/homophobia, as well as to explore the influence of their cultural/ethnic backgrounds on their non-heterosexual identification. I sought to provide answers to these questions through the use of reviewing already existing literature about my topic and population of focus (which was almost non-existent), the findings of which were reflected in my study as well. I also utilised two theoretical frameworks, queer theory and critical race feminism, as the basis from which I operated as a researcher. Both of these theories were able to provide the structure and the nuance around which to frame the findings and analyses.

While the White American-constructed model minority discourse does place East Asians in a privileged position over other racialized groups, it is important to recognize that this does not erase our own distinctive systemic challenges and oppressions. It is dangerous to paint all East Asians with the same brush that designates us as privileged, especially when this brush 
covers over the particular struggles that queer/non-heterosexual East Asian-Canadian women face.

I would like to conclude this study by expressing my immense gratitude, respect, humility, and appreciation to J and Sasha, who were co-researchers much more than they were participants. This research would not have been possible if not for the two of them being open and willing to talk about such heavy and emotionally/spiritually/mentally draining topics. I have learned so much from them and gained a sense of community that I never thought I would have. We do exist and we can and do thrive, especially when we have one another. So thank you, thank you, thank you to them both. 


\section{Appendix A}

\section{Interview Guide}

The interview will begin with collecting participants' age, gender/sex, pronouns, and ethnicity. The following questions will be semi-structured, open-ended, and consist primarily of topics/areas of interest.

- Initial awareness of sexual orientation/gender identity

- Can you tell me what it was like for you when you were initially realizing that you weren't heterosexual/cisgender/gender conforming?

- What were some of the initial challenges or barriers that you came across in the beginning of this journey?

- Exploring sexuality/identity

0 What was your experience like in terms of exploring/coming to terms with your sexuality/gender identity?

- What were/are some of the challenging and/or rewarding parts about it?

- Describe what dating has been like for you. How have you navigated that particular area with regard to your identity?

- The influence of cultural values and expectations

- Can you talk about what it's like to be LGBTQ, East Asian? What is your experience of navigating your sexual orientation/gender identity and your cultural identity?

- Can you tell me about what your family/culture's perspective is on being LGBTQ?

- If you have "come out" to them, what has that process been like for you? If you haven't, can you talk about why not?

- Experience in the LGBTQ+ community

- Can you tell me what your experiences have been like in the larger, "mainstream" LGBTQ+ community in regards to your race, gender, class, ability, age, etc.?

- Do you feel that there is a space for queer East Asian people in the larger community? If not, what are some alternative spaces that you have been a part of or would like to see more of? 


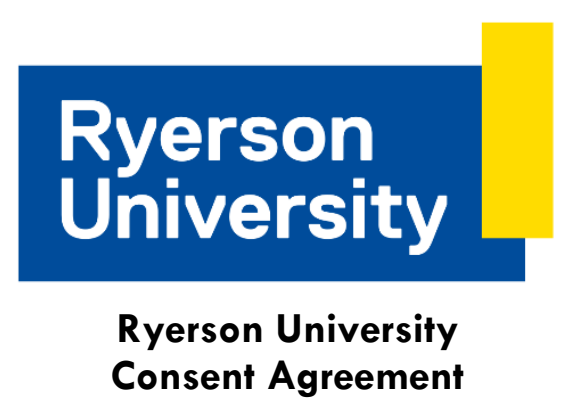

You are being invited to participate in a research study. Please read this consent form so that you understand what your participation will involve. Before you consent to participate, please ask any questions to be sure you understand what your participation will involve.

\title{
TITLE OF THE STUDY
}

Narratives of LGBTQ/WLW-identified East Asian Women in Canadian Society (REB Protocol \#2019-006)

\section{INVESTIGATOR(S)}

This research study is being conducted by Nancy Tran with the assistance and supervision of Dr. Gordon Pon from the School of Social Work [Faculty of Community Services] at Ryerson University. If you have any questions or concerns about the research, please feel free to contact

\author{
Nancy Tran \\ b10tran@ryerson.ca
}

\author{
or \\ Gordon Pon \\ g2pon@ryerson.ca \\ 416-979-5000, ext. 4786
}

\section{PURPOSE OF THE STUDY}

The purpose of this study is to better understand some of the unique experiences that LGBTQ or WLW (woman-loving-women) East Asian-Canadian women face based on their race, sexual orientation/gender identity, and gender. One or two other participants other than yourself will be recruited based on the criteria that they self-identify as being: a woman/woman-identified (femme, female-to-male transman, nonbinary, gender nonconforming), East Asian (Chinese, Korean, Japanese, and/or Vietnamese), and LGTBQ or WLW (woman-loving-woman). Those who do not identify as being all three will not be eligible to participate in this study. This research is being conducted by a graduate student in partial completion of a Master of Social Work (MSW) requirement. The results of this study will contribute to a major research paper to be submitted to the School of Social Work in August of 2019. 
WHAT YOU WILL BE ASKED TO DO

If you volunteer to participate in this study, you will be asked to do the following things:

- Read through and sign the consent form

- Provide your name (a pseudonym will be used in the research), age, gender, ethnicity, phone number and/or email address for demographic purposes

- Arrange a mutually pre-determined date with the primary investigator for one to two hours to meet

- Meet with the primary investigator either in a secure/private office room in the School of Social Work at Ryerson University, or at a mutually determined location which will also hold the same level of privacy and security

- Discuss personal thoughts/feelings/experiences in regards to the interview questions; some examples of questions might be:

- Can you talk about some of your earliest memories/experiences of discovering your sexual/gender identity?

- If you are "out" to anyone in your life, can you talk about what some of the responses that you received were?

- Once the audio-recording of the interview(s) is transcribed, read and approve/disapprove/suggest changes to the transcript within 2 weeks of receiving it by email

If you would like to know what the research findings are, they will be made available directly to you through mail, email, or personal delivery by the primary investigator.

\section{POTENTIAL BENEFITS}

It is the primary investigator's hope that this research will provide you with an opportunity to share your story. In doing so, it is also hoped that this study will be an eye-opening experience for others in recognizing that LGBTQ/WLW East Asian women do exist and have their own unique voices, experiences, and challenges that need to be heard and addressed.

\section{POTENTIAL RISKS TO YOU AS A PARTICIPANT}

It is expected that there will be low/minimal risks to you in participating in this study. In asking for your personal memories and experiences, it is understood that some of the questions may trigger an uncomfortable or upsetting response. At any time, you can decide to not answer a question and/or stop your participation in the study (either temporarily or permanently). A list of organizations and resources will also be provided to you prior to the start of the interview. Due to the personal nature of the interview questions, some experiences described by the participants may be traceable to them depending on who reads the final paper. Despite the usage of pseudonyms, complete and total protection of one's identity cannot be guaranteed, however I will do my best to ensure your confidentiality.

\section{CONFIDENTIALITY}

The primary investigator recognizes that since you are being asked to share highly personal information, your confidentiality is of the utmost importance. Signed consent forms, audio recorded interviews, interview transcriptions, and contact information (names, email, and/or phone number) will be collected. At any time during and 2 weeks after the interview has been 
completed, you have the right to review/edit the recordings or transcripts. You will also be provided with a draft of the final research paper once it is completed.

All data will only ever be kept by the sole investigator, Nancy Tran, and all digital data will be stored electronically under password protection solely in the researcher's personal laptop. Signed consent forms will be kept in a secure locker which is kept in a secure room only accessible to other Master of Social Work students. The audio recordings will be stored on the investigator's password-protected laptop and will be deleted once the transcriptions are completed. This is anticipated to be within a week of the completion of the interview. At this point, the transcriptions will be kept until the final draft of the paper is completed and submitted to the School of Social Work of Ryerson University - this is anticipated for midAugust 2019. Once the paper is submitted to the School of Social Work of Ryerson University the transcriptions will be destroyed. The transcriptions are only kept until final publication for the purpose of being able to review them and write the final research paper.

Only the principal investigator will have access to the research data. However in the event that I have any questions or concerns about the data, I may refer to my supervisor (Gordon Pon) for assistance. I will do my best to maintain your confidentiality and refer to my main concern and not you specifically.

If at any time you disclose to the investigator that there is a threat of harm to yourself, or to someone else, or there is suspicion of child abuse, the investigator has a professional obligation under the Child and Family Services Act to report it to the proper authorities (Children's Aid Society, Toronto Police, etc.). It is under these circumstances only that breaking your confidentiality will be necessary.

\section{INCENTIVES FOR PARTICIPATION}

If you choose to participate in this study, you will be provided with an amount of $\$ 30$ in cash prior to beginning the interview. If you choose to stop your participation at any time, even if the full interview is not completed, you are still entitled to the honorarium.

\section{COSTS OF PARTICIPATION}

Some of the associated costs with participating in this study might include parking fees, public transportation costs, or childcare-related costs in order to meet in person with the investigator. The investigator will provide a reimbursement up to a maximum of $\$ 20$ (in cash) for these costs. This will be provided to you prior to beginning the interview.

Would you like to receive this reimbursement? Please write 'yes' or 'no' here:

\section{VOLUNTARY PARTICIPATION AND WITHDRAWAL}

Your participation in this study is completely voluntary. You do not have to answer every question or complete all aspects of the research. You may stop participating at any point in time during the interview and you will still be given the incentives and reimbursements described above. If you choose to stop participating after having completed the interview, you may also choose to not have your data included in the study within two weeks of the 
interview. If you withdraw from the study, please be assured that this will not influence future relations with the researchers, Ryerson, and any other institutions/partners.

\title{
QUESTIONS ABOUT THE STUDY
}

If you have any questions about the research now, please ask. If you have questions later about the research, you may contact:

\author{
Nancy Tran \\ b10tran@ryerson.ca \\ or \\ Gordon Pon \\ g2pon@ryerson.ca \\ 416-979-5000, ext. 4786
}

This study has been reviewed by the Ryerson University Research Ethics Board. If you have questions regarding your rights as a participant in this study, please contact:

\author{
Research Ethics Board \\ c/o Office of the Vice President, Research and Innovation \\ Ryerson University \\ 350 Victoria Street \\ Toronto, ON M5B 2K3 \\ 416-979-5042 \\ rebchair@ryerson.ca
}

\section{CONFIRMATION OF AGREEMENT}

Your signature below indicates that you have read the information in this agreement and have had a chance to ask any questions you have about the study. Your signature also indicates that you agree to participate in the study and have been told that you can change your mind and withdraw your consent to participate at any time. You have been given a copy of this agreement. You have been told that by signing this consent agreement you are not giving up any of your legal rights.

Name of Participant (please print)

Signature of Participant

Date 
I agree to be audio-recorded for the purposes of this study. I understand how these recordings will be stored and destroyed.

Signature of Participant

Date 


\section{References}

Battle, J., Harris, A., Donaldson, V., \& Mushtaq, O. (2015). Understanding identity making in the context of sociopolitical involvement among Asian and Pacific Islander American lesbian and bisexual women. Women, Gender, and Families of Color, 3(2), 209. doi:10.5406/womgenfamcol.3.2.0209

Chan, C. S. (1989). Issues of identity development among Asian-American lesbians and gay men. Journal of Counseling \& Development, 68(1), 16-20. doi:10.1002/j.15566676.1989.tb02485.x

Carter, S.M. \& Little, M. (2007) Justifying knowledge, justifying method, taking action: Epistemologies, methodologies and methods in qualitative research, Qualitative Health Research, 17(10), 1316-1328.

Cartwright, M. (2012). Confucius. Retrieved from https://www.ancient.eu/Confucius/

Chilisa, B. (2012). Whose reality counts? Research methods in question. In Indigenous research methodologies (pp. 73-96). Los Angeles: SAGE.

Crenshaw, K. (1989). Demarginalizing the intersection of race and sex: A Black feminist critique of antidiscrimination doctrine, feminist theory and antiracist politics. University of Chicago Legal Forum, 1989(1), 8th ser., 139-167.

Gable, S. L., \& Haidt, J. (2005). What (and why) is positive psychology? Review of General Psychology, 9(2), 103-110. doi:10.1037/1089-2680.9.2.103

Han, E., \& O'Mahoney, J. (2014). British colonialism and the criminalization of homosexuality. Cambridge Review of International Affairs, 27(2), 273.

doi:10.1080/09557571.2013.867298 
Hiestand, K. R., Horne, S. G., \& Levitt, H. M. (2007). Effects of gender identity on experiences of healthcare for sexual minority women. Journal of LGBT Health Research, 3(4), 15-27. doi:10.1080/15574090802263405

Ho, R. (2002). Dragon ladies repe(al) the banana: bi-cultural identity formation and Canadianborn women in Vancouver, BC (Ph.D dissertation). University of Toronto.

Hu, X., \& Wang, Y. (2013). LGB identity among young Chinese: The influence of traditional culture. Journal of Homosexuality, 60(5), 667-684. doi:10.1080/00918369.2013.773815

Jones, R. (2014). Divided loyalties: Exploring the intersections of queerness, race, ethnicity and gender. In Critical Articulations of Race, Gender and Sexual Orientation. Edited by Sheena C. Howard. Lexington Books, Maryland 23-46.

Khandkar, S. H. (2009). Open coding. Retrieved from http://pages.cpsc.ucalgary.ca/ saul/wiki/uploads/CPSC681/open-coding.pdf

Lau, L. (2018, July 30). Joel Kim Booster on discovering he's Korean, comedy as defence, and the thirst for diversity. Retrieved from https://www.straight.com/arts/1107821/joel-kimbooster-discovering-hes-korean-comedy-defence-and-thirst-diversity

Logan, C., \& Buchanan, M. (2008). Young women's narratives of same-sex sexual desire in adolescence. Journal of Lesbian Studies, 12(4), 473-500. doi:10.1080/10894160802278655

MacKinnon, K.V.R. (2010). Thinking about queer theory in social work education: a pedagogica 1 in(query). Canadian Social Work Review, 28(1), 139-144.

Mulé, N. (2016). Broadening theoretical horizons: liberating queer in social work academe. In $S$. Hillock \& N. Mule (ed.), Queering Social Work Education. Vancouver: UBC Press. 
Meyer, D. (2012). An intersectional analysis of lesbian, gay, bisexual, and transgender (LGBT) people's evaluations of anti-queer violence. Gender \& Society, 26(6), 849-873. doi:10.1177/0891243212461299

Nadal, K. L., Wong, Y., Issa, M., Meterko, V., Leon, J., \& Wideman, M. (2011). Sexual orientation microaggressions: processes and coping echanisms for lesbian, gay, and bisexual individuals. Journal of LGBT Issues in Counseling, 5(1), 21-46. doi:10.1080/15538605.2011.554606

Neuman, W.L. (2006). The meanings of methodology. In Social research methods: Quantitative and quantitative approaches (6th ed.), (pp. 79-104). Boston: Pearson Education Inc.

Park, H. (1997). Situating East Asians in Canadian race discourse (Unpublished master's thesis). University of Alberta.

Pon, G. (2000). The art of war or the wedding banquet: Asian Canadians, masculinity and antiracism education. Canadian Journal of Education, 25(2), 139-151.

Poon, M. K., Li, A. T., Wong, J. P., \& Wong, C. (2017). Queer-friendly nation? The experience of Chinese gay immigrants in Canada. China Journal of Social Work, 10(1), 23-38. doi:10.1080/17525098.2017.1300354

Poon, O., Squire, D., Kodama, C., Byrd, A., Chan, J., Manzano, L., Bishundat, D. (2016). A critical review of the model minority myth in selected literature on Asian Americans and Pacific Islanders in higher education. Review of Educational Research, 86(2), 469-502. doi:10.3102/0034654315612205

Potts, K. and Brown, L. (2015), Becoming an anti-oppressive researcher. In S. Strega \& L. Brown (Eds.), Research as Resistance: Revisiting critical, Indigenous, and antioppressive approaches (2 ${ }^{\text {nd }}$ ed) (pp. 17 - 42). Toronto: Canadian Scholars' Press. 
Razack, S., Smith, M., \& Thobani, S. (2010). States of race: Critical race feminism for the 21st century. Toronto: Between the Lines.

Rubin, A., \& Babbie, E. (2013). Factors influencing the research process. In Essential research methods for social work ( $3^{\text {rd }}$ ed.) (pp. 49 - 64). Belmont, CA: Brooks/Cole.

Strega, S. (2015). The view from the post-structural margins: Epistemology and methodology reconsidered. In S. Strega \& L. Brown (Eds.), Research as resistance: Revisiting critical, Indigenous, and Anti-oppressive approaches ( $2^{\text {nd }}$ ed) (pp. 119-152). Toronto: Canadian Scholars' Press.

Strega S. \& Brown, L. (2015), From resistance to resurgence. In S. Strega \& L. Brown (Eds.), Research as Resistance: Revisiting critical, Indigenous, and anti-oppressive approaches $\left(2^{\text {nd }} e d\right)($ pp. 1 - 16). Toronto: Canadian Scholars' Press.

Teon, A. (2019, March 12). Filial Piety (孝) in Chinese Culture. Retrieved from https://chinajournal.org/2016/03/14/filial-piety-in-chinese-culture/

Windsor 2016 Census Complete Report. (2018, May 07). Retrieved from https://www.citywindsor.ca/residents/planning/Plans-and-CommunityInformation/About-Windsor/Demographics/Pages/2016-Demographics.aspx

Wing, A. K. (1997). Critical race feminism: A reader. New York: New York University Press.

Wong, J. P., \& Poon, M. K. (2013). Challenging homophobia and heterosexism through storytelling and critical dialogue among Hong Kong Chinese immigrant parents in Toronto. Culture, Health \& Sexuality, 15(1), 15-28. doi:10.1080/13691058.2012.738310

You, Y. G. (1997). Shame and guilt mechanisms in East Asian culture. Journal of Pastoral Care, 51(1), 57-64. Retrieved from 
http://www.jafriedrich.de/pdf/Shame\%20and\%20Guilt\%20Mechanisms\%20in\%20East\% 20Asian\%20Culture.pdf 